\title{
EMOCIONES EN CONTEXTO ELECTORAL Y ATENCIÓN A POLITICA EN MEDIOS: ¿INTELIGENCIA AFECTIVA O EVALUACIÓN COGNITIVA?
}

\author{
Dra. Victoria Isabela Corduneanu \\ Universidad Autónoma de la Ciudad de México \\ isabela.corduneanu@uacm.edu.mx \\ ORCID iD: https://orcid.org/0000-0001-7958-2944 \\ Dr. Carlos Muñiz \\ Universidad Autónoma de Nuevo León, Monterrey, México \\ carlos.munizm@uanl.mx \\ ORCID iD: https://orcid.org/0000-0002-9021-8198 \\ Dr. Martín Echeverría \\ Benemérita Universidad Autónoma de Puebla, Puebla, México \\ echevemartin@yahoo.com.mx \\ ORCID iD: https://orcid.org/0000-0001-6071-8725
}

Recibido el 28 de febrero de 2019

Aceptado el 17 de septiembre de 2019

\begin{abstract}
Resumen
Con base en un estudio cuantitativo longitudinal (tres olas de levantamientos), el presente artículo analiza la evolución de las emociones durante y después de la campaña presidencial del 2018 en México, así como la relación entre las emociones y una forma de participación política de bajo costo, como es la atención a noticias. El estudio se encuadra en la discusión vigente sobre el papel de las emociones en la participación política desde varias perspectivas teóricas, como la Teoría de la Inteligencia Afectiva, la Teoría del Afecto Endógeno, la Teoría de la Transferencia Afectiva, y la Teoría de la Evaluación Cognitiva, que se contraponen a la teoría de la Elección Razonada (rational choice theory). Destacamos, primero, que las emociones durante y después de la campaña tuvieron una evolución hacia su extremo positivo; por otro lado, encontramos evidencias para la teoría de la evaluación cognitiva, pues en el tiempo las emociones mostraron una correlación estadísticamente significativa con la atención a la información, esto es, cuantas más emociones positivas se generaban, más aumentó la atención a las noticias. Luego, estas correlaciones se desagregaron por la cercanía partidista declaradas de los participantes, para las tres olas, encontrando evidencias tanto para la teoría de la inteligencia afectiva en el caso de los independientes, como para la teoría de la evaluación cognitiva para los cercanos a varios partidos.
\end{abstract}

Palabras clave: elecciones, emociones, atención a noticias, cercanía partidista, participación política de bajo costo. 


\title{
EMOTIONS IN ELECTORAL CONTEXT AND POLITICAL ATTENTION TO MASS MEDIA: AFFECTIVE INTELLIGENCE OR COGNITIVE EVALUATION?
}

\begin{abstract}
Based on a three-waves longitudinal survey, this paper analyzes the changes in emotions during and after the presidential campaign in Mexico in 2018, as well as the relationship between emotions and a "low cost political participation", such as attention to news. The research makes a contribution to the current debate on the role of emotions on political participation, from various theoretical perspectives, such as the Theory of Affective Intelligence, the Theory of Endogenous Affect, the Theory of Affect Transfer and the Theory of Cognitive Evaluation, all opposed to Rational Choice Theory. We found that emotions changed from more negative to more positive ones, during and after the campaign. In regard to the relationship of emotions and attention to news, we found support for both the Theory of Affective Intelligence, among the nonpartisan participants, and for the Theory of Cognitive Evaluation, among the participants who declared a party partisanship.
\end{abstract}

Keywords: electoral campaigns, emotions, attention to news, low cost political participation, party partisanship. 
Introducción

$\mathrm{L}$

a campaña electoral de 2018 en México se destacó por el uso de las emociones por parte del candidato ganador, Andrés Manuel López Obrador. De acuerdo a Aceujo (2018), su victoria es producto del papel de las emociones en la toma de decisiones, incluyendo el voto. El candidato presidencial usó como emoción estandarte una de tipo positivo: la esperanza, y también un motivador más apropiado de las movilizaciones sociales: el cambio. La autora menciona que, además de estas dos líneas discursivas, su discurso, en vez de propuestas racionales de política pública, estaba repleto de emociones positivas (además de la esperanza del cambio): alegría, orgullo, euforia, simpatía, confianza, optimismo, éxtasis y admiración.

Este artículo se propone estudiar las emociones de los electores durante y después de la campaña electoral, tanto en general, para ver la evolución de estas emociones durante la campaña, como en particular, indagando en el papel de las emociones positivas y negativas en los hábitos informativos de los participantes, durante y después de la campaña electoral. Se toma en cuenta, por un lado, el contexto electoral mexicano atípico, con un candidato puntero a una distancia de más de 30 puntos de los demás, y haciendo una campaña repleta de emociones positivas.

Por otro lado, nos situamos teoréticamente en los estudios sobre el papel de las emociones en la participación política, desde varias perspectivas epistemológicas como la sociología de las emociones, o desde aspectos teóricos más concretos, como la Teoría de la Inteligencia Afectiva (Marcus, Neuman y MacKuen, 2000, citados por Groenendyk, 2011, Marcus, Mackuen y Neuman, 2011) o la Teoría del Afecto Endógeno y del Transfer Afectivo (Ladd y Lenz, 2008 y 2011), así como la Teoría de la Evaluación Cognitiva (Valentino et al., 2011). Atendiendo a lo planteado por estos últimos autores, se asumirá en este artículo la atención a contenidos políticos en medios como la manifestación de una participación política de bajo costo, en tanto que implica una actividad de no tal alto costo como pueden ser otras manifestaciones de la participación política, como asistir a mítines o ser voluntario en la campaña (Valentino et al., 2011).

En concreto, el artículo se plantea como primer objetivo analizar el cambio en las emociones positivas y negativas durante y después de la campaña electoral de julio 2018, en México. Asimismo, también se busca determinar las posibles asociaciones existentes entre la atención prestada por los participantes a la política en los medios (participación política de bajo costo) durante la campaña electoral y las emociones sentidas hacia la política y los políticos por parte de los ciudadanos durante el paso proceso electoral mexicano de 2018, tanto en población en general, como en los segmentos que se identifican como independientes o cercanos a algún partido. 


\section{De la sociología de las emociones al giro afectivo en las ciencias sociales.}

El presente artículo se inscribe en un campo de conocimiento más extenso que el papel de las emociones en la política. En concreto estamos hablando de la sociología de las emociones, que renacen desde los años 70s (Marcus, 2000: 221). En la visión de J.M. Barbalet, "las emociones se deben entender no solo como un aspecto de la cultura, sino como parte de las relaciones de poder y de estatus que las produce. Eso hace que las emociones, más que un aspecto cultural, sean un aspecto de estructura social" (Barbalet, 1998: 26).

En palabras de Barbalet, uno de los autores seminales en la sociología de las emociones, ninguna acción (e incluimos aquí la acción política), puede ocurrir en la sociedad (entendida esta como un sistema interactivo) sin la implicación emocional de los actores (Barbalet, 2002: 1-9).

El estudio de las emociones y del afecto no se quedaron en la sociología, si no que traspasaron rápidamente el campo de la teoría de la acción social y de la psicología, para extenderse a los estudios culturales y a la teoría cultural. Para Lara y Enciso (2013), el momento del boom de las teorías del afecto se sitúa en 1995, con dos autores: Brian Massumi, quien se apoya fuertemente en la obra de Deleuze para "criticar las limitaciones de las perspectivas discursivas y para abogar por el afecto y su autonomía con respecto al discurso;" y Eve Sedgwick quién también sostiene las críticas a la perspectiva discursiva pero incorpora la perspectiva teórica del psicólogo Silvan Tomkins: el afecto está conectado con alguna emociones básicas, como la vergüenza, el miedo, el enojo, la excitación, la alegría y el asco (Lara y Enciso, 2013: 103). Así, la incorporación del afecto y de las emociones en los estudios culturales se da como una crítica al giro lingüístico de las mismas y marcará un regreso del sujeto y de sus emociones a las ciencias sociales.

Patricia Clough fue la primera en usar el término de "giro afectivo" y lo define como el enganche teórico con las emociones y la afectividad que se da en las ciencias sociales y en las humanidades a partir de la segunda mitad de los 90s (Athanasiou, Hantzaroula y Yannakopoulos, 2009: 5). A su vez, Arfuch (2016: 248) define el giro afectivo como "la creciente atención a las emociones como fuente privilegiada de verdad sobre el sujeto" y lo ve como una reacción al giro textual o lingüístico, el cual abogaba por la primacía del discurso y un olvido del cuerpo y de las emociones, debido a la influencia del psicoanálisis y del postestructuralismo.

El giro afectivo ha propuesto temas específicos de investigación, como la relación entre poder, subjetividad y emoción; la dimensión afectiva de lo normativo; la carga emotiva y afectiva de las normas sociales, y, lo que nos ocupa en este artículo, el lugar de las emociones en las teorías políticas (Athanasiou, Hantzaroula y Yannakopoulos, 2009: 5). Otro tema importante han sido los efectos sociales que generan las emociones en los discursos públicos, como el amor, el odio, la pena, el miedo, la vergüenza, planteando una interrogante: ¿qué hacen las emociones con nosotros? (Arfuch, 2016: 250). 


\section{Emociones y política: entramados teóricos.}

Una premisa fundamental para nuestro tema es que las emociones movilizan: "Las emociones son una parte medular de la acción. (...) Si hemos de comprender las acciones emprendidas, necesitamos entender las emociones que las conducen, acompañan y son resultado de ellas" (Jasper, 2013: 61). Es por eso que, según James Jasper, es justo el "giro afectivo" el que nos puede ayudar a entender los mecanismos ocultos de acción social, que ni la teoría racional, ni la teoría crítica o interpretativa pudieron entender, justo por estar paradas sea solo en la razón, sea solo en el texto.

La teoría de la elección racional (rational choice theory) ha sido cuestionada en las últimas décadas desde la perspectiva del enganche emocional en la política: los individuos participan porque les importa, les preocupa o sienten pasión (emoción) sobre un tema o un problema (Wahl-Jorgensen, 2016: 116). En las palabras de Redlawsk, Tolbert y Franko (2010: 876): "las emociones deben ser vistas como una parte integral del proceso de toma de decisiones políticas."

En su libro The Political Brain (El cerebro político), Drew Westen (2007) afirma que: "el cerebro político es un cerebro emocional." No es una máquina de cálculo sin pasiones, que buscar de manera objetiva los datos correctos, los números y los hechos para poder hacer una decisión razonada," pues hasta los votantes bien informados y con consciencia política pueden tomar decisiones "con corazonadas" (citado por Wahl-Jorgensen, 2016: 116).

Desde la sociología de las emociones se ha criticado la teoría de la elección racional por ser más una metáfora que una representación exacta de los eventos, esto es, de los cálculos de costes y beneficios que, según esta teoría, se involucra en la toma de decisiones, incluyendo el voto y otras formas de participación política. En palabras de Barbalet (2002: 3) los costes y los beneficios de la mayoría de las acciones no se pueden conocer mas que después de que la acción se concluya, por lo tanto, no existe información relevante para tomar una decisión con base en un cálculo. Este autor argumenta que la función de las emociones es precisamente la resolución de problemas y la anticipación sobre si una experiencia va a ser placentera o dolorosa, positiva o negativa.

Las ciencias políticas, desde los 80s, toman en cuenta las emociones y el afecto, junto con la ya mencionada crítica a la teoría de la elección racional; un tema predilecto ha sido la predicción del voto a través de la evaluación de las reacciones emocionales de los electores a los estímulos políticos, la influencia del atractivo de un candidato sobre su evaluación, o las emociones que generan también las instituciones políticas, el nacionalismo o los temas y posicionamientos políticos (Marcus, 2000). El primer estudio sobre las emociones políticas es el de Abelson, et al. (1982) con datos del American National Election Study (ANES): encontraron que las emociones positivas y negativas se separaban en dos dimensiones bien 
delimitadas, y estas dimensiones predecían fuertemente las preferencias sobre los candidatos, aun después de controlar la variable de opiniones sobre la personalidad de los candidatos (Groenendyk, 2011: 460).

Por otro lado, usando modelos psicológicos del afecto, G.E. Marcus encuentra que las respuestas emocionales positivas a un candidato (tomando en cuenta las reacciones a las características personales de un candidato y su trabajo), son dos veces más importantes que las respuestas negativas para poder predecir el voto. La conclusión del estudio es que son las respuestas emocionales las que determinan la implicación de los individuos en la política, y que las emociones, más que subjetivas, se constituyen en conocimientos estratégicos (1988: 755).

Desde entonces, se ha formado un consistente corpus de estudios que exaltan el papel positivo de las emociones en crear motivaciones para la participación política en varias formas, desde ir a votar, a participar en campañas, o durante la socialización política. En palabras de Groenendyk (2011: 459), "las emociones son vitales para entender cuándo y por qué los votantes buscan información política, cómo esta información se transforma en evaluaciones políticas, y cuándo los ciudadanos son suficientemente motivados para participar en política." En estos desarrollos se han elaborado varias teorías o modelos sobre el papel de las emociones en las actitudes y comportamientos políticos.

Brader (2011: 342) cataloga las teorías sobre las emociones en la comunicación política en dos grandes grupos. Por un lado, son las teorías que consideran los efectos directos o causales de las emociones sobre las actitudes y los comportamientos políticos, como: la teoría de la "Cognición Cálida" (hot cognition theory, en inglés), elaborada por Lodge y Taber, que se discute a continuación. Otro grupo de teorías que discuten el efecto directo de las emociones sobre el comportamiento son la teoría de la evaluación cognitiva, elaborada por Schwarz y Clore o el modelo de la infusión del afecto, elaborado por Forgas. Estas teorías postulan que los individuos toman decisiones para enfrentar a sus emociones, y las personas usan a sus emociones como una fuente de información sobre el mundo de alrededor y para ayudarles a tomar decisiones y a actuar (Valentino et. al, 2011: 159).

Por otro lado, está la Teoría de la Inteligencia Afectiva, que asigna a las emociones un papel indirecto o mediador, elaborada por Marcus, Neuman y MacKuen (2000, citados por Groenendyk, 2011, Marcus, Mackuen y Neuman, 2011).

Inicialmente conocido como "el modelo dual del razonamiento motivado", este modelo tenía como hipótesis central la "cognición cálida", que sugiere que todos los conceptos sociopolíticos tienen una carga afectiva. Todos los líderes políticos, grupos, problemáticas, símbolos e ideas, que se evaluaron en el pasado, se cargan afectivamente (sea positiva o negativamente) y este afecto se vincula directamente al concepto en la memoria a largo plazo donde se almacena. Este registro 
evaluativo se recuerda de manera automática cuando se es expuesto al objeto político al cual está asociado el registro: en presencia del estímulo, lo que se recuerda es la asociación afectiva junto con la asociación cognitiva. La teoría del razonamiento motivado vincula el afecto y la cognición con un concepto que se almacena en la memoria a largo plazo; en el proceso de razonamiento, este concepto se recuerda, se baja a la memoria a corto plazo, pero se baja con los dos registros, el afectivo y el cognitivo. Así, las emociones vinculadas a un concepto, se transforman en información (Lodge y Taber, 2005: 456). En la presencia de un estímulo (por ejemplo, un líder político, un problema, cierto grupo social), la carga afectiva se activa desde la memoria a largo plazo y se integra a cualquier evaluación que se haga del estímulo presente.

Además, la teoría de la cognición cálida implica que todas las representaciones sociopolíticas de la memoria a largo plazo pueden ser y son activadas espontáneamente con la exposición al estímulo: una activación espontánea del afecto o de la emoción (Morris, et al., 2003: 727).

Lodge y Taber (2005) discuten dos implicaciones importantes del modelo de la cognición cálida. La primera tiene que ver con la "acción racional" de los ciudadanos, y la conclusión de los autores es que los ciudadanos internalizan solo evaluaciones sumarias de políticos, temáticas y grupos socio-políticos, evaluaciones que se forman espontáneamente en un proceso continuo de encontrar información. Así, se forman etiquetas o vínculos entre temas y afectos, que se constituyen en una guía heurística para comportamiento futuro y futuras actitudes. La segunda implicación tiene que ver con el procesamiento de la información: los ciudadanos desarrollan dos sesgos para la selección de la información. El primero es de noconfirmación, cuando aceptan información congruente con sus actitudes y contraargumentan los hechos o datos contrarios con ellas (especialmente entre los sujetos con actitudes fuertes). El segundo sesgo es de confirmación, cuando buscan activamente información que puede confirmar sus actitudes preexistentes. Ambos sesgos llevan a la polarización de las actitudes, sobre todo en los sujetos más sofisticados y con actitudes más fuertes (Lodge y Taber, 2005: 476). En un estudio posterior, Taber y Lodge (2006) ponen a prueba los sesgos de no-confirmación y de confirmación y encuentran nuevamente que las actitudes o creencias preexistentes sesgan el procesamiento de nueva información sobre líderes políticos, grupos sociales o políticos y temáticas sociales y políticas, a través de un escepticismo motivado por actitudes y creencias preexistentes (lo que los transforma en un sesgo) hacia información que no es congruente con estas dos dimensiones.

La importancia del modelo dual del razonamiento motivado, con su hipótesis de la cognición cálida, reside en la contribución al estudio de las actitudes políticas, pues se vinculan los afectos, las actitudes políticas y el comportamiento político, poniendo el lente en la importancia de las emociones en este proceso. 
Posteriormente, los autores desarrollan un modelo más completo, denominado "John Q. Public," cuya premisa fundamental es que las reacciones cognitivas y afectivas a eventos externos e internos, son detonadas de manera inconsciente, y son seguidas de una difusión de activación a través de líneas de asociaciones que vinculan pensamientos con sentimientos, intenciones y comportamientos, de tal manera que los primeros eventos, aun los que son inconscientes, establecen la modalidad de procesar todos los eventos que les sigue (Taber y Lodge, 2016: 63).

Lo importante de este modelo es poner en perspectiva, por un lado, el papel de los afectos no intencionales (por ejemplo, los colores o la música de fondo de un spot publicitario electoral, como lo discute el estudio de Brader, 2006). Por otro lado, también se visibiliza el papel de las actitudes preexistentes (que están también cargadas de "registros afectivos"), en la construcción de las decisiones políticas. En los dos casos, primero se hace una evaluación del "objeto" (evento, grupo, persona, temática), y luego se toma una decisión; lo que también en persuasión se ha llamado "ruta periférica". La única "ruta central" es la que lleva del objeto directamente a la decisión pasando por "consideraciones" y "construcción de argumentos" (Marañón, Muñiz y Saldierna, 2017: 151).

Relacionado con este modelo, está el de la Teoría de la Inteligencia Afectiva, el cual propone que las emociones de una persona influyen en las actitudes y el comportamiento político de dos maneras: en ausencia de afectos negativos, se propicia una confianza en las decisiones políticas habituales; en presencia de afectos negativos, se propicia atención, búsqueda y valoración de nueva información política. Marcus, Mackuen y Neuman (2011), a través de análisis de datos de American National Election Survey (ANES), descubren que, cuando los ciudadanos sienten ansiedad sobre el candidato de su partido, construyen su decisión de voto no solo con base en la cercanía partidista, sino que además consideran la personalidad y las propuestas del candidato (p. 323). En otras palabras, en vez de una decisión automática, basada en afectos, empiezan una búsqueda activa de información y un proceso de racionalización de su decisión, más allá de la dimensión afectiva de la identidad partidista.

La Teoría de la Inteligencia Afectiva estipula que los ciudadanos usan sus emociones para manejar su atención sobre el mundo de la política. Extrapolando desde la neurociencia, hay dos sistemas emocionales distintos. Un "sistema disposicional", que incluye las emociones y sentimientos normales, y un "sistema de vigilancia", que se encarga de poner atención en las cosas. El "sistema de vigilancia" depende de emociones neurológicamente distintas, sobre todo, ansiedad, miedo o incertidumbre; estas emociones señalan que algo está fuera de la rutina, y que es necesaria una atención consciente (buscar información, valorar, juzgar), más allá de los hábitos (o las acciones automáticas o sobreentendidas, como votar por el candidato del partido con el cual se siente identificado) (Marcus, Mackuen y Neuman, 2011: 324). 
De manera complementaria, entonces, la Teoría de la Inteligencia Afectiva profundiza en el vínculo entre emociones, actitudes políticas y comportamientos, detallando en emociones, como la ansiedad, y en comportamientos políticos específicos, como búsqueda de información para votar, en vez de confiar en "hábitos", como votar por el candidato del partido con el cual el elector siente más cercanía. También, la Inteligencia Afectiva matiza las conclusiones del modelo de la Cognición Cálida, introduciendo en la ecuación el papel del "sistema de vigilancia" que hace que los sujetos no actúen de acuerdo a los hábitos influidos por afectos preexistentes.

Ladd y Lenz (2008 y 2011), critican el modelo de la Inteligencia Afectiva y proponen otras dos alternativas explicativas: la teoría del transfer afectivo y la teoría del afecto endógeno. La teoría del transfer afectivo postula que las reacciones emocionales positivas y negativas de los ciudadanos a los candidatos políticos, les "transfieren" directamente cualidades positivas y negativas a los candidatos. La argumentación está basada en la intuición de que, si alguien te hace sentir ansioso, te va a gustar menos, y si te hace sentir feliz, te va a gustar más. Mientras que la teoría del afecto endógeno revierte la relación causal que propone la Inteligencia Afectiva: las evaluaciones preexistentes de los candidatos determinan reacciones emocionales. Los candidatos que no gustan crean ansiedad, mientras que los candidatos que gustan, crean entusiasmo; así, muchas actitudes y creencias, reflejan o racionalizan las preferencias hacia candidatos y partidos (Ladd y Lenz, 2008: 276-277).

Sin embargo, estos planteamientos no contradicen totalmente el modelo de la Inteligencia Afectiva, porque el modelo demuestra el efecto de la ansiedad sobre el comportamiento del elector para tomar una decisión informada (a través de la búsqueda de información), en vez de votar de acuerdo a sus preferencias partidistas; sin embargo, no se demuestra el efecto de la ansiedad sobre el voto final. Esto es, un elector que sienta ansiedad, buscará más información política, pero eso no garantiza que va a cambiar el sentido de su voto.

Estas posiciones teóricas abonan a la presente reflexión sobre el papel de las emociones en las votaciones del 1ero de julio del 2018, así como justifica teoréticamente el planteamiento de investigar las emociones personales antes, durante y después de la campaña electoral del 2018.

\section{Emociones y política: una multiplicidad de aproximaciones.}

Además de los abordajes teóricos, los trabajos empíricos han puesto atención en otras preguntas: ¿Qué movilizan más, las emociones negativas o las emociones positivas? No hay una respuesta definitiva a esta interrogante; además, no todos los autores revisan las mismas emociones, como veremos; para algunos son más importantes las emociones positivas, para otros las emociones negativas; algunos otros autores escogen estudiar las emociones en pares, como en el caso del estudio que aquí presentamos. A continuación, revisaremos algunos de los estudios más importantes en la materia, de acuerdo a las emociones que están estudiando. 
De acuerdo a Marcus, MacKuen y Neuman (2011: 331), hay tres dimensiones emocionales que afectan la atención en la política: entusiasmo (felicidad), aversión (enojo) y ansiedad. Cada una tienen sus propias consecuencias: el entusiasmo determina una participación activa, la aversión determina evitar las personas, la participación y así como reacciones defensivas de motivación racional, mientras que la ansiedad determina la atención y el aprendizaje (o búsqueda de información).

Como parte del debate que abren con Marcus y sus colegas, Ladd y Lenz (2011) desarrollan un estudio sobre el papel del entusiasmo en la participación política, con datos longitudinales del ANES y encuentran que el entusiasmo tiene interacciones similares a las de la ansiedad con la preferencia electoral y la simpatía partidista. Como variable, en vez de la ansiedad que un votante siente para el candidato de su partido, estos autores usan el entusiasmo que se siente para el candidato del partido contrario a sus preferencias. Los hallazgos indican que el entusiasmo tiene un efecto similar a la ansiedad: se reduce el efecto de la preferencia partidista sobre la preferencia del voto y aumenta el efecto de las propuestas del candidato, (Ladd y Lenz, 2011: 352-353). Así, el entusiasmo para el candidato del partido contrario hace que el votante ponga más atención en sus propuestas y disminuye la preferencia del voto de acuerdo al partidismo del votante. Este efecto es todavía más interesante cuando hay candidatos carismáticos, pues nos puede hacer pensar que, en este caso, el efecto del partidismo en la preferencia del voto disminuye drásticamente.

Tenemos, por lo tanto, conclusiones sobre el papel complementario del entusiasmo y de la ansiedad sobre actitudes, creencias y comportamiento político. En un estudio longitudinal con datos de American National Election Survey (ANES) de 1996, 2000, 2004 y 2008, Wang (2013) investigó el papel del diferencial emocional (la diferencia de las emociones positivas y negativas reportadas para cada candidato, demócrata y republicano) y el diferencial de identificación partidista sobre la probabilidad de ir a votar; encuentra que las dos variables tienen el mismo impacto sobre el voto, lo que lo lleva a concluir que la decisión del voto es el resultado tanto de las emociones como de la racionalidad. Nuevamente, se precisa que las emociones tienen mayor impacto sobre el voto cuando los candidatos son personas carismáticas (como las elecciones de 1996, con Clinton y 2008 con Obama), lo que aumenta el entusiasmo que se siente por estos candidatos.

Además del entusiasmo, otra emoción que ha sido estudiada en relación con la participación política es la ansiedad. Como ya mencionamos, el trabajo de Marcus, MacKuen y Neuman (2011) sugiere que es la ansiedad (emoción opuesta al entusiasmo o la felicidad) la que señala que "hay algo fuera de rutina" $y$, como parte del "sistema de vigilancia", detona la atención al entorno, la búsqueda de información; en el caso del voto, el votante no solo vota en automático de acuerdo a sus preferencias partidistas, sino que empieza un proceso de decisión informada y consciente, tomando en cuenta las características personales del candidato y sus propuestas. El resultado final puede ser votar por el candidato de su partido, o 
votar por otro candidato. En otras palabras, los autores no demuestran que la ansiedad influye en la preferencia del voto, sino que detona un proceso de vigilancia y de búsqueda de mayor información, así que la decisión final es una decisión informada, más allá del partidismo: detona la inteligencia afectiva. En otras palabras, el entusiasmo hace que el votante se comporte de acuerdo a sus preferencias partidistas (vota en automático por el candidato del partido con el cual se identifica), mientras que la ansiedad detona un proceso de racionalización del voto, acompañado de mayor atención al entorno, a las noticias y búsqueda de información.

Construyendo sobre los hallazgos de Marcus y sus colegas, Brader (2005) se enfoca en la relación entre la publicidad política, las emociones y el comportamiento político. A través de dos experimentos, el autor busca el efecto de las emociones usadas y transmitidas en spots políticos durante las campañas sobre el comportamiento de los votantes Las emociones que se presentan en los spots son en concreto entusiasmo y miedo. Sus hallazgos confirman y complementan la Teoría de la Inteligencia Afectiva de Marcus, Mackuen y Neuman, (2011). Los votantes entusiastas confían más en creencias y actitudes preexistentes, ya adquiridas (como la preferencia partidista o su ideología), mientras demuestran mayor interés en la participación en la campaña (interés en la campaña o interés para ir a votar), y menor vigilancia; mientras que los votantes expuestos a mensajes de miedo (o ansiedad) aumentan sus niveles de vigilancia y de búsqueda de información. La consideración de las temáticas políticas vigentes (presentes en los discursos de los candidatos) tiene mayor importancia en su decisión de voto que lealtades preexistentes, como la identificación partidista. No se encuentra evidencia sobre el papel movilizador del miedo (Brader, 2005: 397-402). En otras palabras, las campañas basadas en miedo, tienen un efecto contrario: si bien no movilizan al voto, tampoco desmovilizan y solo aumenta la atención a la información y la búsqueda de más información. Adicionalmente, el planteamiento de Brader (2005 y 2006) llama la atención sobre la importancia de las emociones en las campañas electorales, y, concretamente, en los anuncios publicitarios de campaña, así como sobre los recursos estilísticos y técnicos que se usan para que permeen en el público.

Valentino et al (2011) estudian el papel de las emociones positivas (entusiasmo, orgullo y esperanza) y de las emociones negativas (ansiedad y enojo) sobre dos formas de participación política: de bajo costo (hablar con otras personas, llevar un distintivo de campaña) y de alto costo (participar en mítines, ser voluntario en la campaña, donar dinero). De manera complementaria a los estudios ya mencionados, los autores encuentran que la ansiedad puede tener un efecto movilizador sobre formas de participación de bajo costo, o bien, puede tener un papel desmovilizador sobre la participación política en general. Al contrario, el enojo tuvo efectos significativos y fuertes sobre formas de participación de alto costo, mientras que las emociones positivas tuvieron efectos positivos, mas no fuertes, sobre la participación. 
De igual manera, en el caso del Brexit, las emociones que movilizaron el voto a favor del Brexit fueron las negativas: miedo, desafección y enojo que sentía la clase trabajadora y la clase media- baja contra el estatus-quo político. La desafección, entendida como falta de optimismo y lejanía de los mecanismos del poder, fue todavía más azuzada por los políticos que legitimaban este (re)sentimiento (WahlJorgensen, 2016: 116).

En un interesante estudio comparativo entre Holanda, Israel e Italia, Van Zomeren et al., (2018) estudian el papel del enojo en la movilización al voto, además del papel de la identificación partidista y de la eficacia partidista. Sus hallazgos contradicen la hipótesis de que el enojo es solo un síntoma del cinismo político, pues encuentran que, mientras en Holanda y en Israel el enojo con la política en general tienen como efecto desmotivar el voto (cinismo político), en Italia este enojo aumentó la intención del voto, por lo tanto, el enojo es también una variable contextual; el estudio se hizo en el contexto de las elecciones de 2012-2013 en estos países; en particular, en Italia es el Movimiento Cinco Estrellas que captó el enojo contra el sistema político en general y lo capitalizó en votos (p. 335). Los autores encuentran que el enojo moviliza al voto cuando tiene un papel similar a la rabia en las movilizaciones sociales, esto es, en vez de ser un enojo generalizado con la política (que puede aumentar el cinismo político), es un enojo que incluye el deseo de cambio de sistema, como en el caso del Movimiento Cinco Estrellas en Italia. Es interesante el paralelismo con el caso italiano, pues en el caso mexicano, MORENA también transformó el "enojo con la política en general" con una campaña electoral cuyos temas centrales han sido el cambio y la esperanza, en un discurso altamente emotivo. Es importante destacar la conclusión de los autores sobre el papel coyuntural y contextual de las emociones, sobre todo del enojo, que no tiene los mismos efectos en varios contextos: sí logra movilizar en Italia, pero tiene el efecto contrario en otros dos contextos (Holanda e Israel).

Para el caso de México, un estudio de Rosario Aguilar (2013) usa los planteamientos de la Teoría de la Inteligencia Afectiva, así como los planteamiento de Brader (2006) sobre los componentes emocionales en los comerciales de campaña para analizar los spots de tres de los candidatos presidenciales en la campaña de 2012: Enrique Peña Nieto, por el Partido Revolucionario Institucional, Josefina Vázquez Mota, por el Partido Acción Nacional (el partido en el poder) y Andrés Manuel López Obrador (por el Partido de la Revolución Democrática) (Aguilar, 2013). Tomando en cuenta el contexto de nuestro estudio, rescatamos las conclusiones de la autora, sobre la predominancia de las emociones positivas (orgullo, esperanza y entusiasmo) en los spots del candidato puntero, Enrique Peña Nieto, cuyo efecto sería afianzar las lealtades existentes (la decisión de voto con base en la cercanía partidistas). Aunque el artículo no hace un análisis del impacto de las emociones detectadas en el material publicitario sobre el comportamiento electoral, es interesante tomar en cuenta que, desde el 2012, estas emociones se estaban poniendo en "circulación" en el imaginario mexicano, sobre todo la emoción positiva que será el gran lema de campaña de Andrés Manuel López Obrador: la esperanza. De manera similar, 
Marañón, Muñiz y Saldierna (2017), en un análisis de spots políticos encuentran que aquellos que usan las emociones (o la ruta periférica de persuasión) generan menor desafección política y tienen una valoración más positiva que los spots con mensajes racionales o la ruta central, aunque también generan menor conversación política (p. 156).

Teniendo en cuenta estos antecedentes, y apoyándonos sobre todo en los planteamientos de la Teoría de la Inteligencia Afectiva, el presente artículo trabajará con las siguientes preguntas de investigación:

Pl1: ¿Cómo han evolucionado en la población en general las emociones autoreportadas al principio, a la mitad y después de la campaña presidencial de 2018 en México?

$\mathrm{PI2} \quad$ ¿Cómo evolucionan estas emociones en los tres tiempos de levantamiento (o las tres olas), tomando en cuenta la cercanía partidista reportada?

PI3: ¿En las tres olas, la atención a las noticias impacta a las emociones o viceversa?

PI4: De acuerdo a la cercanía partidista reportada, en las tres olas, ¿la atención a las noticias impacta en las emociones o viceversa?

\section{Metodología}

Groenendyk (2011: 460) sugiere que los estudios sobre las emociones deberían traspasar el debate sobre cuál tiene más influencia en la participación política: la cognición o el afecto. En vez de este debate, el autor sugiere hacer estudios longitudinales capaces de sorprender el desarrollo de las emociones en el tiempo, para evitar preguntar sobre emociones pasadas (recordación de emociones), pues en esta autoevaluación, la cognición ya juega un papel importante. Tomando en cuenta esta sugerencia, en este estudio escogimos un modelo longitudinal y de reactivo inmediato (la emoción que se reporta en el momento de escuchar el estímulo). De manera precisa: se hicieron tres olas de levantamiento, como se precisa más abajo, y preguntó sobre qué sentían los participantes al escuchar las palabras "política y políticos".

Para la realización del estudio ${ }^{1}$, se contrató a la empresa demoscópica Survey Sampling International (SSI), con el objeto de contar con una muestra amplia y lo más representativa posible de la población mexicana, a la par de garantizar la participación de los mismos participantes en las diferentes olas del estudio. La primera ola se realizó la semana previa al inicio oficial de elecciones, comenzando el 23 de marzo y terminando la aplicación el 30 de marzo. En dicha aplicación se levantaron un total de 1,819 entrevistas en línea. La segunda ola se realizó durante

\footnotetext{
1 Esta investigación fue financiada con los proyectos del Consejo Nacional de Ciencia y Tecnología (CONACYT) titulados "Análisis de la cobertura mediática de las campañas electorales y su impacto en la desafección política y el compromiso democrático ciudadano" (Clave 280739) y "Infoentretenimiento político, encuadres periodísticos y desconfianza ciudadana" (Clave 256670)
} 
el mes de junio de 2018, con el objetivo de registrar actitudes y comportamientos con respecto a los primeros dos meses de campaña electoral. El levantamiento se realizó entre el 1 y el 25 de junio de 2018, participando finalmente una muestra de 996 entrevistados en la ola primera. La última aplicación se realizó una vez pasada la elección y cuando los conteos distritales quedaron realizados, por lo que el trabajo de campo comenzó el 9 de julio y terminó el 19 de ese mes. En total participaron 701 entrevistados que también contestaron la primera y segunda ola.

Muestra. De los datos obtenidos, únicamente se contó con los relativos a los participantes que fueran mayores de edad ( $\geq 18$ años) y censados como votantes en la República. En este sentido, en la muestra final $(N=701)$ participaron ciudadanos de todos los estados de la República, así como de Ciudad de México. Un 54.8\% de la muestra estaba constituido por hombres $(n=384)$, por un $45.2 \%$ de mujeres ( $n=$ 317), con edades comprendidas entre 18 y 80 años $(M=42.07, D E=13.37)$. En la muestra se contemplaron participantes con diferentes niveles educativos, siendo el grupo mayoritario el correspondiente a aquellos que tenían estudios profesionales $(n=424,60.7 \%)$ o de preparatoria $(n=130,18.6 \%)$.

Asimismo, un $43.6 \%$ de participantes reportaron unos ingresos mensuales de entre $\$ 10,001.00$ y $\$ 30,000.00(n=285)$, un $40 \%$ menores a $\$ 10,001.00(n=202)$ y un $25.4 \%$ de más de $\$ 30,001.00(n=166)$. Cabe mencionar que, si bien se buscó la mayor representatividad de la muestra, las características sociodemográficas de la misma imposibilitan su generalización total. Con todo, se asume que la muestra es aceptable para este tipo de estudios pues, al proceder de una encuesta panel, garantiza un control total a pesar de ser más bien una muestra analítica y posibilita, en cualquier caso, el contraste de los cambios en emociones y comportamientos a lo largo del tiempo.

\section{Medidas utilizadas.}

Emociones hacia la política y los políticos. Se cuestionó a los participantes qué sentimientos les ocasionaba escuchar la palabra "política" o "políticos", a partir de un diferencial semántico de Osgood compuesto por 4 escalas bipolares medidas con siete puntos cada una de ellas, en cuyos extremos se presentaban los siguientes sentimientos o emociones antónimas: ansiedad-tranquilidad, alegríarabia, frustración-orgullo y confianza-desconfianza, emociones escogidas con base en otros estudios que se han hecho sobre emociones y actitudes y comportamiento político como Marcus, MacKuen y Neuman (2011), Ladd y Lentz (2008 y 2011), sobre el papel de la ansiedad en la participación política, o el estudio de Valentino et al (2011) y Van Zomeren et al (2018) sobre el papel del enojo, la ansiedad y el entusiasmo en la participación política. Estas escalas se ilustran en la siguiente tabla: 
Tabla 1. Escala de medición de emociones mantenidas durante la campaña

\begin{tabular}{rllllllll}
\hline Ansiedad & 1 & 2 & 3 & 4 & 5 & 6 & 7 & Tranquilidad \\
Alegría & 1 & 2 & 3 & 4 & 5 & 6 & 7 & Rabia \\
Frustración & 1 & 2 & 3 & 4 & 5 & 6 & 7 & Orgullo \\
Confianza & 1 & 2 & 3 & 4 & 5 & 6 & 7 & Desconfianza \\
\hline
\end{tabular}

Con el objetivo de construir una escala que midiera las emociones sentidas en su conjunto, se procedió a invertir las puntuaciones en las escalas segunda y cuarta, para que el indicador final estuviera balanceado de una emoción negativa hacia una positiva. Se evaluó para cada una de las olas si la escala contaba con validez de constructo y fiabilidad, obteniéndose buenos datos tanto para la ola primera (KMO $\left.=.764, R^{2}=68.73, \alpha=.848\right)$, como la segunda $\left(\mathrm{KMO}=.771, R^{2}=69.24, \alpha=.852\right) \mathrm{y}$ tercera $\left(\mathrm{KMO}=.770, R^{2}=72.57, \alpha=.874\right)$.

Atención a política en medios de comunicación. Para este estudio en específico, escogimos detallar el efecto de las emociones sobre una forma de participación política de "bajo costo", la atención a noticias, tomando como modelo la Teoría de la Inteligencia Afectiva, así como los planteamientos teóricos complementarios revisados. Al respecto, cabe mencionar que la variable de atención a contenidos de política en medios es una medida habitualmente utilizada en estudios de comunicación política para evaluar el consumo mediático selectivo realizado por las personas para conocer sobre política.

Con el objetivo de crear un indicador de atención a política en medios de comunicación para informarse política general, se preguntó a los participantes con qué frecuencia, en una escala de Likert que oscilaba entre nunca (1) y muy frecuentemente (5) consumían los siguientes contenidos mediáticos: noticias en periódicos en papel, noticias en periódicos digitales, programas de política de la radio, noticias de la radio, programas de política en la televisión y noticias en la televisión. El nivel de consistencia interna de las escalas fue aceptable tanto para la primera ola $(M=3.28, D E=0.96, \alpha=.79)$, como para la segunda $(M=3.17, D E=$ $1.01, \alpha=.80)$ y la tercera $(M=3.20, D E=0.98, \alpha=.79)$.

Variables de control. Finalmente, se contempló el uso de una serie de variables de control de carácter sociodemográfico. En concreto, se les cuestionó a los participantes acerca de su género $(0=$ masculino; $1=$ femenino) y su edad, en años cumplidos. También se pidió que indicaran cuál era, aproximadamente, el nivel de ingresos mensual de su núcleo familiar, con una escala que oscilaba entre menos de 6,000 pesos mexicanos (1) y más de 30,001 pesos mexicanos (4). También, se evaluó de forma adicional el nivel de estudios de los participantes, con una escala que osciló entre no tiene (1) y estudios de posgrado (7). 


\section{Resultados y discusión}

En un estudio preliminar (Corduneanu, 2019) se presentaron los resultados generales del estudio, esto es, la evolución de las emociones en los tres momentos, que retomamos aquí para contextualizar nuestros hallazgos.

Tabla 2. Comparación de las emociones de los participantes en los tiempos de la encuesta panel

\begin{tabular}{lllllll}
\hline & \multicolumn{2}{l}{ Tiempo 1} & \multicolumn{2}{l}{ Tiempo 2 } & \multicolumn{2}{l}{ Tiempo 3 } \\
\cline { 2 - 7 } & $M$ & $D E$ & $M$ & $D E$ & $M$ & DE \\
\hline Ansiedad-Tranquilidad & $2.68^{\star \star \star}$ & 1.30 & $2.72^{\star \star \star}$ & 1.34 & $2.89^{\star \star \star}$ & 1.42 \\
Rabia-Alegría & $2.46^{\star \star \star}$ & 1.35 & $2.57^{\star \star \star}$ & 1.40 & $2.78^{\star \star \star}$ & 1.45 \\
Frustración-Orgullo & $2.43^{\star \star \star}$ & 1.42 & $2.46^{\star \star \star}$ & 1.39 & $2.72^{\star \star \star}$ & 1.51 \\
Desconfianza- & $2.10^{\star \star \star}$ & 1.37 & $2.27^{\star \star \star}$ & 1.47 & $2.47^{\star \star \star}$ & 1.50 \\
Confianza & $2.42^{\star \star \star}$ & 1.13 & $2.50^{\star \star \star}$ & 1.17 & $2.72^{\star \star \star}$ & 1.25 \\
Índice de emociones & & & & &
\end{tabular}

Nota: $N=701$. Todas las variables se midieron con diferenciales semánticos de 7 puntos, entre ambos polos de la emoción. ${ }^{\star \star \star} p<.001$

De manera general, en ninguna de las olas se superó la media teórica de las emociones medidas $(M=4)$, lo que indica que la tendencia fue a una puntuación en las emociones hacia el extremo negativo de la emoción más que hacia el positivo. En cuanto a las comparaciones de la presencia de cada emoción o sentimiento, así como del indicador de emociones sentidas creado, a lo largo de los tres tiempos de la encuesta panel, se observa en general que la puntuación tiende a ser más positiva conforme avanza la campaña para todas las mediciones (Ver Tabla 1).

Para realizar el análisis de la presencia de cada emoción en las diferentes etapas de campaña se hizo uso de un Análisis Factorial de Varianza (UNIANOVA), que permite comparar medias en más de dos grupos. En cuanto al diferencial entre AnsiedadTranquilidad, se encontraron diferencias estadísticamente significativas, $F(2,1385)=$ 8.697, $p<.001, \eta_{\text {parcial }}{ }^{2}=.012$. Ahora bien, para poder determinar entre qué etapas del proceso electoral en concreto se situaban las diferencias, se procedió a realizar un análisis de las medias marginales estimadas, mediante el ajuste de Bonferroni. El análisis arrojó una diferencia entre el tiempo 3 (julio) con los otros dos tiempos (marzo-junio), que no divergieron entre sí. El análisis del diferencial entre RabiaAlegría arrojó diferencias estadísticamente significativas, $F(2,1400)=18.151, p$ $<.001, \eta_{\text {parcial }}{ }^{2}=.025$, presentándose las diferencias también entre el tiempo 3 y los tiempos 1 y 2 en conjunto.

Por otra parte, el análisis del diferencial entre Frustración-Orgullo arrojó diferencias estadísticamente significativas, $F(2,1400)=15.434, p<.001, \eta_{\text {parcial }}{ }^{2}=.022$. En 
general, se detectó una puntuación mayor hacia la emoción positiva en el tiempo 3 (julio) que en los tiempos 1 y 2 (marzo-junio), que no difirieron entre sí en cuanto a la presencia de estas emociones. Finalmente, el diferencial entre DesconfianzaConfianza también presentó diferencias estadísticamente significativas, $F(2,1400)=$ 20.092, $p<.001, \eta_{\text {parcial }}{ }^{2}=.028$. Sin embargo, en este caso los tres tiempos presentaron diferencias entre sí, atendiendo al análisis de las medias marginales estimadas, mediante el ajuste Bonferroni, realizado. Como se puede observar, la tendencia hacia la confianza tendió a aumentar con el tiempo, sin sobrepasar en ningún momento la medición el punto intermedio $(M=4)$. En cuanto al índice creado, se presentaron diferencias estadísticamente significativas entre los tiempos de aplicación, $F(2,1380)=28.478, p<.001, \eta_{\text {parcial }}{ }^{2}=.039$, puntuando el índice en mayor medida en el tiempo 3 que en los tiempos 1 y 2, que no difirieron entre sí.

Posteriormente, se realizó el mismo análisis de comparación de las emociones, pero segmentando entre la cercanía a los diferentes partidos políticos (Ver Tabla 2). Atendiendo a las respuestas, se trabajó con cinco grupos o perfiles de participantes: cercanos al PAN, al PRI, a Morena, a otros partidos y no cercanos a ningún partido. Se observa que los cercanos al PRI no presentaron ninguna variación, mientras que los cercanos al PAN y a otros partidos presentaron variaciones sutiles en algunas emociones o sentimientos. Los cercanos a otros partidos tendieron a mejorar su confianza después de las elecciones, $F(2,90)=3.575, p=.038, \eta_{\text {parcial }}{ }^{2}=.065$. Por su parte, los cercanos al PAN tuvieron un aumento de puntuación en frustraciónorgullo entre la primera y tercera ola, $F(2,214)=3.429, p=.034, \eta_{\text {parcial }}{ }^{2}=.031$, y mejoraron su emoción general hacia la política y políticos en la tercera ola, frente a la primera y segundas en conjunto, $F(2,214)=4.259, p=.015, \eta_{\text {parcial }}{ }^{2}=.038$.

Por su parte, los no cercanos a ningún partido político presentaron diferencias estadísticamente significativas en todas las emociones y sentimientos. En concreto, presentaron mayores puntuaciones en la tercera ola, frente a las restantes en conjunto, para los diferenciales de Ansiedad-Tranquilidad, $F(2,656)=4.821, p$ $=.008, \eta_{\text {parcial }}^{2}=.014$, Rabia-Alegría, $F(2,656)=9.493, p<.001, \eta_{\text {parcial }^{2}}=.028$, Frustración-Orgullo, $F(2,656)=7.315, p=.008, \eta_{\text {parcial }}{ }^{2}=.022$, y en el índice general de emociones ante la política y los políticos, $F(2,656)=17.133, p=.008, \eta_{\text {parcial }}{ }^{2}$ $=.050$. Sin embargo, en el diferencial Desconfianza-Confianza la diferencia se presentó entre la primera ola, donde la desconfianza fue más pronunciada, y la segunda y tercera olas, donde se matiza aunque siga siendo fuerte, $F(2,656)=$ $15.183, p=.008, \eta_{\text {parcial }}{ }^{2}=.044$. 
- Victoria Isabela Corduneanu, Carlos Muñiz, Martín Echeverría

Tabla 3. Comparación de las emociones de los participantes en los tiempos de la encuesta panel, segmentando por cercanía partidista

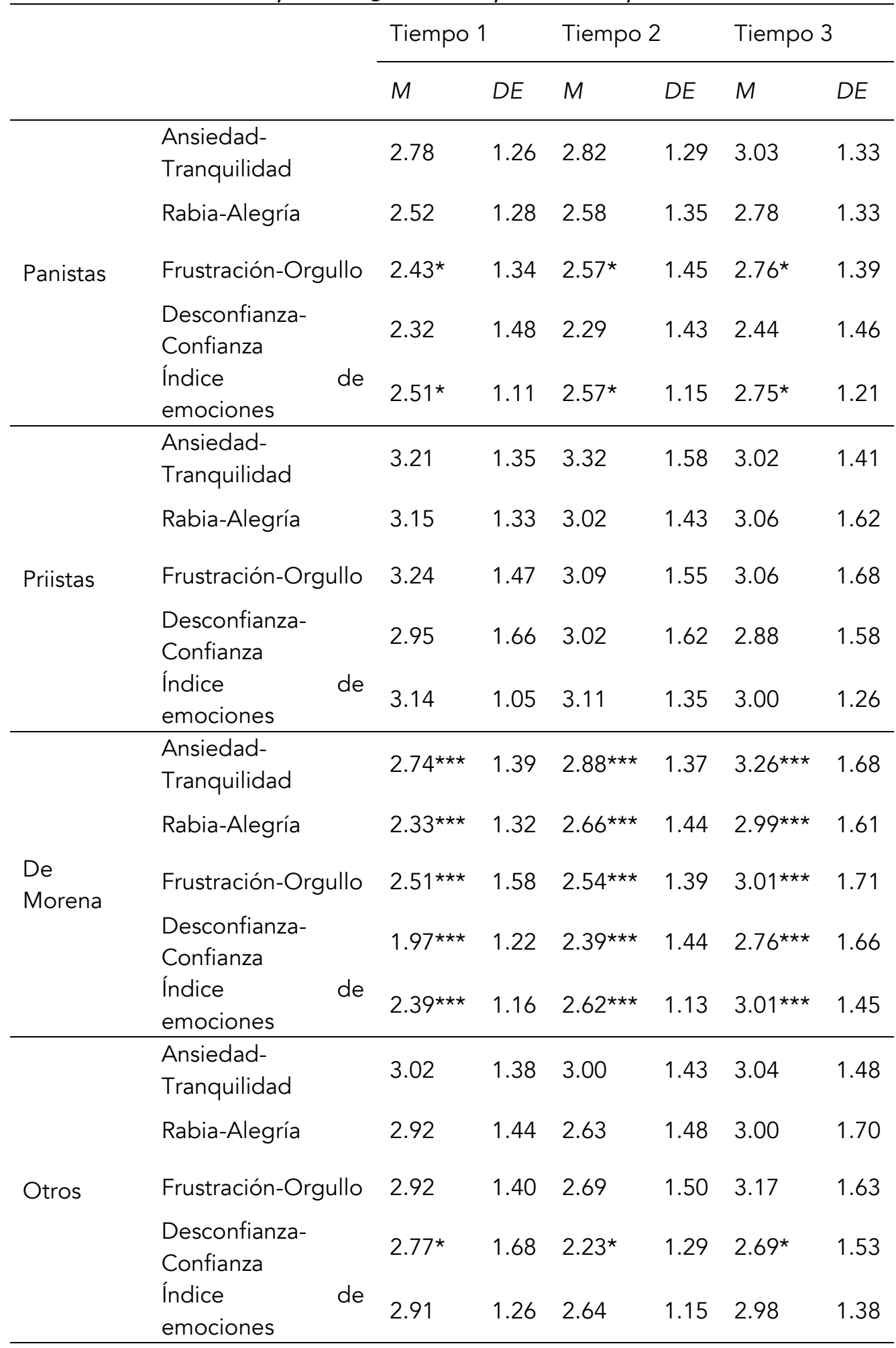




\begin{tabular}{|c|c|c|c|c|c|c|c|}
\hline & $\begin{array}{l}\text { Ansiedad- } \\
\text { Tranquilidad }\end{array}$ & $2.45^{\star \star \star}$ & 1.21 & $2.44^{\star \star \star}$ & 1.21 & $2.63^{\star \star \star}$ & 1.27 \\
\hline & Rabia-Alegría & $2.28^{\star \star \star}$ & 1.31 & $2.43^{\star \star \star}$ & 1.37 & 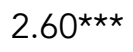 & 1.32 \\
\hline \multirow{3}{*}{$\begin{array}{l}\text { No } \\
\text { cercanos }\end{array}$} & Frustración-Orgullo & $2.16^{\star \star \star}$ & 1.29 & $2.22^{\star \star \star}$ & 1.27 & $2.43^{\star \star \star}$ & 1.35 \\
\hline & $\begin{array}{l}\text { Desconfianza- } \\
\text { Confianza }\end{array}$ & $1.81^{\star \star \star}$ & 1.14 & $2.07^{\star \star \star}$ & 1.44 & $2.24^{\star \star \star}$ & 1.37 \\
\hline & $\begin{array}{l}\text { Índice } \\
\text { emociones }\end{array}$ & $2.18^{\star \star \star}$ & 1.03 & $2.29^{\star \star \star}$ & 1.10 & $2.48^{\star \star \star}$ & 1.10 \\
\hline
\end{tabular}

Nota: $N=701, n_{\text {Panistas }}=108 ; n_{\text {Priistas }}=66 ; n$ De Morena $=146 ; n_{\text {Otros }}=52,{ }_{n N o \text { cercanos }}=$ 329. Todas las variables se midieron con diferenciales semánticos de 7 puntos, entre ambos polos de la emoción. ${ }^{\star \star \star} p<.001$

Finalmente, los participantes que indicaron ser cercanos a Morena también presentaron diferencias estadísticamente significativas en todas las emociones y sentimientos, siendo quienes mostraron cambios más pronunciados, aunque sus emociones nunca llegaran a superar la media teórica $(M=4)$. En cuanto al diferencial de Ansiedad-Tranquilidad, estos participantes presentaron un cambio sustancial entre la primera y la tercera olas, con un aumento sustancial en tranquilidad, $F(2,267)=6.736, p=.002, \eta_{\text {parcial }}{ }^{2}=.044$.

En cuanto al diferencial Rabia-Alegría, también se presentó un aumento en la segunda ola respecto a la primera, manteniéndose en la ola posterior a la elección este nivel de alegría, $F(2,290)=10.805, p<.001, \eta_{\text {parcial }}{ }^{2}=.069$. Por parte, tanto en el diferencial Frustración-Orgullo, $F(2,268)=7.642, p=.001, \eta_{\text {parcial }}{ }^{2}=.050$, como en el de Desconfianza-Confianza, $F(2,290)=15.716, p<.001, \eta_{\text {parcial }}{ }^{2}=.098$, se presentaron mayores puntuaciones en la tercera ola. Así, los participantes puntuaron más en estos sentimientos después de las elecciones que en los momentos anteriores. Finalmente, se observó que el índice general de emociones aumentó en cada ola con respecto a la anterior, notándose así un efecto del transcurso de la campaña electoral, $F(2,265)=15.824, p<.001, \eta_{\text {parcial }}{ }^{2}=.098$.

En la segunda fase del estudio, se procedió a determinar las asociaciones existentes entre la atención prestada por los participantes a la política en los medios durante la campaña electoral y las emociones sentidas hacia la política y los políticos, para lo que se utilizó el Índice de emociones calculado. Con ello, se pretendía no sólo evaluar las correlaciones existentes entre ambas variables en cada ola, sino más bien conocer si se producía algún tipo de correlación desfasada en el tiempo (crosslagged correlation), y determinar si en el tiempo la atención impactaba en las emociones o viceversa. Para ello, se procedió a utilizar el estadístico RozelleCampbell, que arroja un valor a partir de determinar el "nivel de correlación que se espera sobre la base de las autocorrelaciones y las correlaciones síncronas" en los tiempos medidos (Lopez-Escobar et al., 1998: 233). 


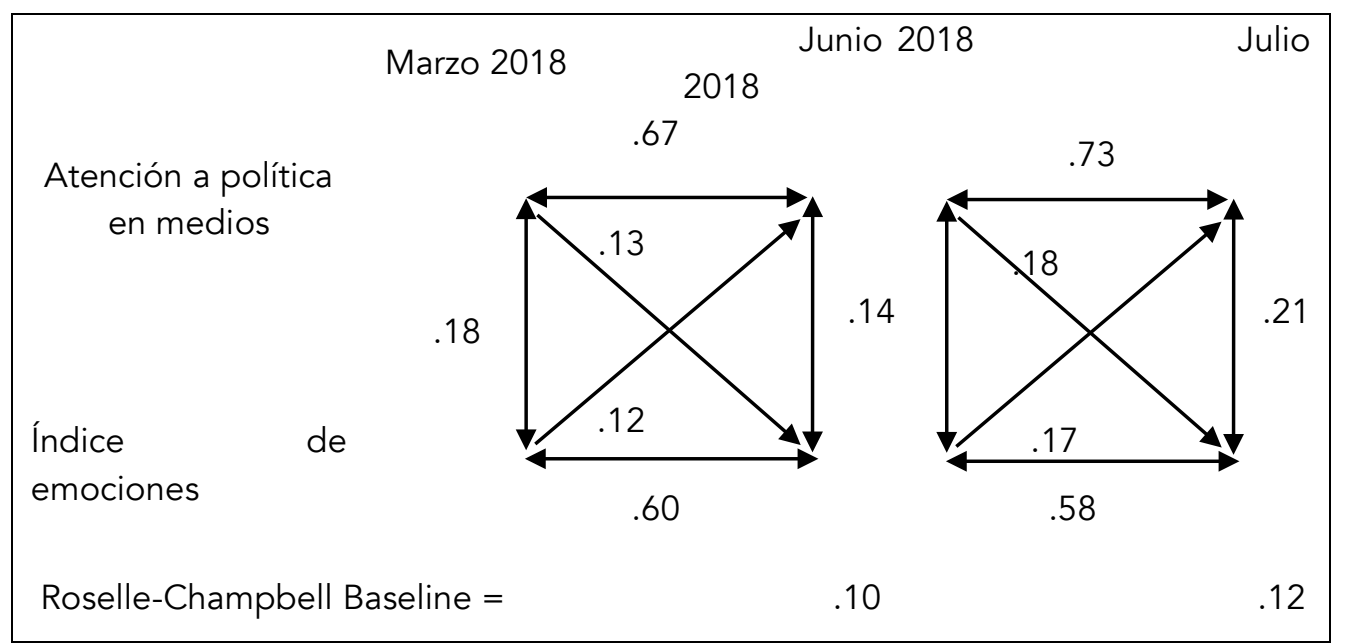

Figura 1. Correlaciones desfasadas en el tiempo entre la atención a política en medios y el índice de emociones sentidas hacia la política y los políticos, entre los diferentes tiempos de campaña

Nota: $N=701$. Se controlaron las variables sexo $(1=$ mujer $)$, edad, ingreso mensual del hogar y nivel de estudios del encuestado.

En este sentido, primero se calculan las seis posibles correlaciones entre las dos variables (Kenny y Harackiewicz, 1979): las correlaciones sincrónicas dentro de cada ola, expresadas como PX1Y1 y PX2Y2, las autocorrelaciones de cada variable entre el tiempo 1 y 2, expresadas como PX1X2 y PY1Y2 y, finalmente, las dos correlaciones desfasadas en el tiempo entre las dos variables desde el tiempo 1 al 2, expresadas como PX1Y2 y PX2Y1. A partir de las primeras cuatro correlaciones se calcula la línea de base o estadístico Rozelle-Campbell, que se expresa en un valor que oscila entre -1 y 1 , y se calcula utilizando la siguiente fórmula (Lopez-Escobar et al., 1998; Roberts y McCombs, 1994): [(PX1Y1 +/PX2Y2)/2][(PX1X2) $\left.\left.+/(\text { PY1Y2 })^{2}\right] / 2\right\}^{1 / 2}$. Una vez calculada la línea de base, se determinará que las correlaciones desfasadas son significativas cuando su valor de asociación supere el del estadístico Rozelle-Campbell.

Atendiendo a que el estudio panel constó de tres olas, se calcularon los valores de la línea de base Roselle-Champbell entre los tiempos 1 y 2 y los tiempos 2 y 3 , para determinar el impacto de cada tipo de variable en la otra a lo largo del tiempo. Además, y al objeto de controlar la influencia de las variables sociodemográficas estudiadas, se trabajó con correlaciones parciales. Como se puede observar en la figura 1, el valor del estadístico Roselle-Champbell para la comparación entre la ola 1 y 2 del total de la muestra fue de .10, superando el mismo las dos correlaciones desfasadas en el tiempo el mismo. Sin embargo, se observa que fue mayor el impacto de la atención a política en medios sobre las emociones, $r_{\text {parcial }}(646)=.13, p$ $<.001$, que al contrario. Por su parte, el valor de la línea de base entre los tiempos 
2 y 3 fue de .12, detectándose de nuevo un mayor impacto de la atención a política en medios sobre las emociones, $r_{\text {parcial }}(646)=.18, p<.001$, que al contrario.

Atención a política
en medios

Figura 2. Correlaciones desfasadas en el tiempo entre la atención a política en medios y el índice de emociones sentidas hacia la política y los políticos, entre los diferentes tiempos de campaña, para los cercanos al PAN

Nota: $N=108$. Se controlaron las variables sexo $(1=$ mujer $)$, edad, ingreso mensual del hogar y nivel de estudios del encuestado.

Con el objetivo de hacer un análisis más pormenorizado de cada grupo de la población, se segmentó la muestra total por cercanía partidista. En cuanto a los que indicaron considerarse cercanos al PAN (Ver Figura 2), se procedió al cálculo de las correlaciones desfasadas entre las dos variables a largo del tiempo. En cuanto a la comparación entre la ola 1 y 2 , el valor del estadístico Roselle-Champbell fue de .06, superando sólo una correlación desfasada en el tiempo el mismo. Se observa, por tanto, que entre los panistas en la primera etapa de campaña fue significativo únicamente el impacto de las emociones sobre la atención a política en medios, $r_{\text {parcial }}(98)=.10, p=.316$. Por su parte, el valor de la línea de base entre los tiempos 2 y 3 fue de .05 , detectándose en este momento de la campaña un cambio entre los panistas, pues aquí fue mayor impacto de la atención a política en medios sobre las emociones, $r_{\text {parcial }}(98)=.11, p=.275$, que al contrario.

Por su parte, también se hizo el cálculo de las correlaciones entre etapas para los que se declararon cercanos al PRI (Ver Figura 3), detectándose en la comparación entre la ola 1 y 2 un valor del estadístico Roselle-Champbell de .11. En este caso, sólo una correlación desfasada en el tiempo superó este valor, pudiéndose determinar por tanto que entre los priistas en la primera etapa de campaña sólo fue significativo el impacto de la atención a política en medios sobre las emociones, $r_{\text {parcial }}(54)=.37, p=.002$. Por su parte, el valor de la línea de base entre los tiempos 2 
y 3 fue de .09, detectándose en este momento de la campaña que las dos correlaciones eran significativas, al superar ambas la línea de base. Sin embargo, en la última etapa de la campaña se produjo un cambio entre los priistas, pues aquí fue mayor impacto de las emociones sobre la atención a política en medios, $r_{\text {parcial }}(54)=.16, p=.231$, que al contrario.

Atención a política
en medios

Figura 3. Correlaciones desfasadas en el tiempo entre la atención a política en medios y el índice de emociones sentidas hacia la política y los políticos, entre los diferentes tiempos de campaña, para los cercanos al PRI

Nota: $N=66$. Se controlaron las variables sexo $(1=$ mujer $)$, edad, ingreso mensual del hogar y nivel de estudios del encuestado.

En cuanto a los participantes que se declararon cercanos a MORENA (Ver Figura 4), el cálculo de las correlaciones entre las dos variables realizado para las olas 1 y 2 arrojó un valor del estadístico Roselle-Champbell de .05, lo que permitió determinar que sólo una correlación desfasada fue significativa. En este caso, sólo superó el valor de la línea de base el impacto de las emociones sobre la atención a política entre los morenistas, $r_{\text {parcial }}(138)=.14, p=.102$. Por su parte, el valor de la línea de base entre los tiempos 2 y 3 fue de .07 , detectándose en este momento de la campaña que las dos correlaciones eran significativas, al superar ambas la línea de base. Sin embargo, en la última etapa de la campaña se produjo un cambio entre los morenistas, pues aquí fue mayor impacto de la atención a política en medios sobre las emociones, $r_{\text {parcial }}(138)=.22, p=.010$, que al contrario. 
.63

Atención a política en medios

Índice de emociones

Roselle-Champbell Baseline =
1

.09

4

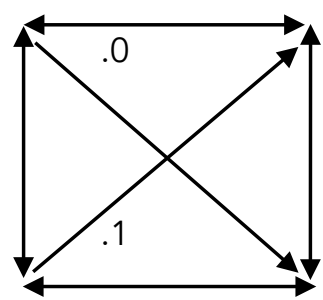

.51
.65

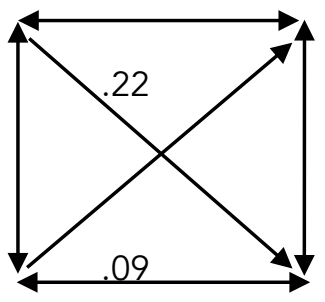

.38

Figura 4. Correlaciones desfasadas en el tiempo entre la atención a política en medios y el índice de emociones sentidas hacia la política y los políticos, entre los diferentes tiempos de campaña, para los cercanos a MORENA

Nota: $N=146$. Se controlaron las variables sexo $(1=$ mujer $)$, edad, ingreso mensual del hogar y nivel de estudios del encuestado.

Atención a política en medios

Figura 5. Correlaciones desfasadas en el tiempo entre la atención a política en medios y el índice de emociones sentidas hacia la política y los políticos, entre los diferentes tiempos de campaña, para los cercanos a otros partidos

Nota: $N=52$. Se controlaron las variables sexo $(1=$ mujer $)$, edad, ingreso mensual del hogar y nivel de estudios del encuestado.

En un bloque conjunto se situó a todos aquellos que, aun considerándose cercanos a partidos, no lo hicieron por ninguno de los anteriores; ni PAN, ni PRI, ni MORENA (Ver Figura 5). El cálculo de las correlaciones entre las dos variables realizado para 
las olas 1 y 2 arrojó un valor del estadístico Roselle-Champbell de .03, lo que permitió determinar que sólo una correlación desfasada fue significativa. En este caso, sólo superó el valor de la línea de base el impacto de las emociones sobre la atención a política entre los participantes, $r_{\text {parcial }}(41)=.12, p=.442$. Por su parte, el valor de la línea de base entre los tiempos 2 y 3 fue de .10, detectándose en este momento de la campaña dos correlaciones significativas, al superar ambas la línea de base. Además, en la última etapa de la campaña se produjo un cambio entre estos participantes, pues aquí fue significativo el impacto de la atención a política en medios sobre las emociones, $r_{\text {parcial }}(41)=.30, p=.054$.

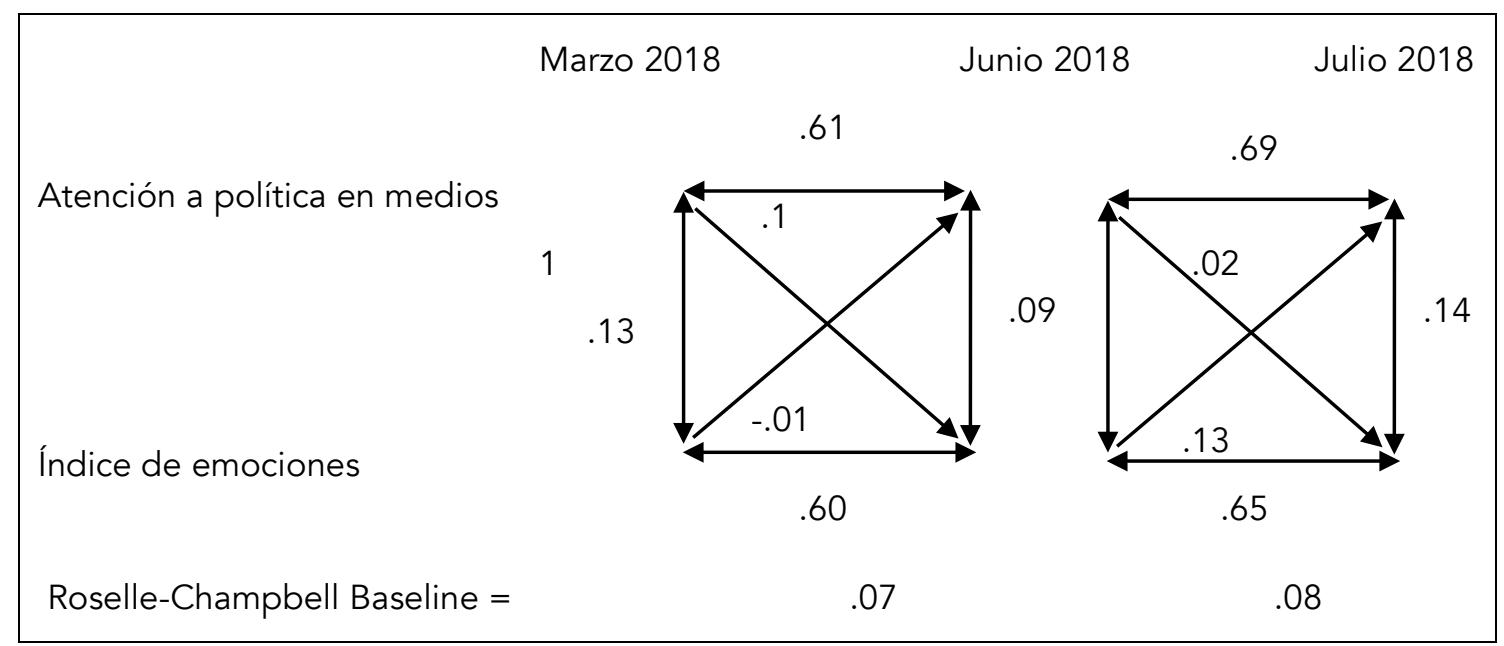

Figura 6. Correlaciones desfasadas en el tiempo entre la atención a política en medios y el índice de emociones sentidas hacia la política y los políticos, entre los diferentes tiempos de campaña, para los no cercanos a partidos

Nota: $N=329$. Se controlaron las variables sexo $(1=$ mujer $)$, edad, ingreso mensual del hogar y nivel de estudios del encuestado.

En último lugar, se trabajó con el grueso de participantes que dijeron no sentirse cercanos a ninguno de los posibles partidos existentes (Ver Figura 6). El cálculo de las correlaciones entre las dos variables realizado para las olas 1 y 2 arrojó un valor del estadístico Roselle-Champbell de .07, lo que permitió determinar que sólo una correlación desfasada fue significativa. En este caso, sólo superó el valor de la línea de base el impacto de la atención a política entre los participantes sobre sus emociones hacia la política y los políticos, $r_{\text {parcial }}(291)=.11, p=.072$. Por su parte, el valor de la línea de base entre los tiempos 2 y 3 fue de .08, detectándose en este momento de la campaña únicamente una correlación significativa que superó la línea de base. En esta última etapa de la campaña, se observa un cambio entre los no cercanos a partidos, pues el impacto significativo entre estas dos etapas fue el de las emociones mantenidas por los participantes sobre su atención a política en medios, $r_{\text {parcial }}(291)=.13, p=.028$. 


\section{Conclusiones}

La novedad de este estudio es la de proporcionar un seguimiento longitudinal, con tres olas de levantamiento (dos durante la campaña electoral y una posterior), lo que nos permite ver un desarrollo en el tiempo de las emociones y de las actitudes políticas auto-reportadas (mas no recordadas).

Nuestro primer objetivo fue estudiar si la campaña impactó en las emociones reportadas, tanto en población en general, como en los segmentos con varias identificaciones partidistas.

Para contestar nuestra primera pregunta de investigación sobre la evolución de las emociones durante y después de la campaña, de manera general, se observa que las emociones reportadas tienden hacia el extremo negativo, pero hubo una evolución estadísticamente significativa hacia el extremo positivo de una ola a otra, aunque sin pasar por encima de la media teórica; comparando los tres tiempos, se encuentran diferencias estadísticamente significativas solo para el tiempo 3 (después de las elecciones) comparado con las dos olas previas (campaña) para orgullo, tranquilidad, y alegría; mientras que las diferencias para confianza fueron estadísticamente significativas entre el tiempo 1 y 2 también. Por lo tanto, podríamos concluir que la campaña impactó de manera positiva solo sobre la confianza, mientras que los resultados de la elección impactaron de manera positiva y significativa sobre todas las emociones, hacia el extremo positivo.

Nuestra segunda pregunta de investigación desagrega la evolución de las emociones en los tres tiempos de levantamiento, pero ahora en función de la cercanía partidista.

Entre los panistas, se dio un aumento en el orgullo en la tercera ola (después de las elecciones), frente a las dos otras olas (en campaña). Los priistas no mostraron fluctuaciones significativas entre las olas, tampoco los que se identificaban con partidos menores, solo en el caso de la confianza, cuyo aumento fue significativo en la tercera ola (después de las elecciones).

El caso más interesante es el de los cercanos a MORENA y el de los independientes, quienes mostraron fluctuaciones significativas hacia las emociones positivas. En el caso de los independientes, la diferencia es positiva y significativa entre la tercera ola (después de las elecciones) y las primeras dos en conjunto (la campaña) para la alegría, la tranquilidad y el orgullo. Sin embargo, es interesante ver que, en el caso de la desconfianza, esta es más pronunciada entre la primera y la segunda y tercera ola; aunque para la tercera ola se matiza, la desconfianza (en políticos y política) siguen siendo fuerte entre los independientes. En el índice general de emociones, también hay una diferencia significativa a favor de las emociones positivas en la tercera ola, frente a las primeras dos en conjunto. Esto es, el resultado de las elecciones aumentó las emociones positivas entre los independientes, mientras que la fluctuación en la desconfianza (en políticos y la política) está más matizada. 
En el caso de los cercanos a MORENA, los cambios en las emociones son más pronunciados, aunque tampoco sus emociones llegan a superar la media teórica (esto es, tienen tendencia a emociones negativas). El orgullo, la tranquilidad y la confianza puntuaron mejor en la tercera ola (después de las elecciones) que en las primeras dos (durante la campaña, donde no hubo diferencias significativas entre las dos olas). Sin embargo, la alegría sí presentó diferencias entre las tres olas, lo que nos remite a los estudios sobre el papel movilizador del entusiasmo versus el enojo en las campañas políticas (Ladd y Lenz, 2011; Wang, 2013, Valentino et al, 2011). Será materia de otro estudio establecer las correlaciones entre este par de emociones y formas de participación política reportadas, incluyendo la intención de voto y posteriormente, el voto. Por lo pronto, lo que se puede afirmar es que el enojo entre los partisanos de MORENA disminuyó en la segunda ola y de manera significativa, después de la campaña. Se puede decir que la campaña y luego los resultados de las elecciones tuvieron mayor impacto emotivo (hacia lo positivo) en los independientes y los cercanos a MORENA, los que, probablemente, fueron los más enganchado en o los más pendientes del proceso electoral.

Como conclusión del primer objetivo tenemos que las emociones durante y después del proceso electoral de julio 2018 en México se diferenciaron entre los independientes y Morena, por un lado, quienes reportan más enganche emocional, $y$, por otro lado, los PRIstas, PANistas y simpatizantes de otros partidos, quienes reportaron menor enganche emocional. También, el efecto de la campaña y de los resultados sobre las emociones en su conjunto fue positivo, y de manera estadísticamente significativa este efecto positivo se expresó en los independientes y los cercanos a MORENA. Por lo tanto, podemos decir que el impacto de la campaña en las emociones fue mediado por la identificación partidista.

El segundo objetivo fue analizar las asociaciones existentes entre la atención a las noticias en los medios y las emociones reportadas hacia la política y los políticos, tomando como referencia los estudios del impacto de las emociones sobre las actitudes políticas, y la participación política. Tomando en cuenta el diseño longitudinal del estudio, de manera específica propusimos analizar si, en el tiempo, la atención a las noticias impactaba en las emociones o viceversa.

En todos los tres tiempos se detecta una correlación mayor a nivel estadístico de las emociones (agrupadas en el índice de las emociones) con la atención a la política. En el tiempo, esta correlación aumenta de la ola 1 a la ola 3 (después de la campaña), esto es: cuantas más emociones positivas se generaban (de acuerdo a las conclusiones del primer objetivo), más aumentó la atención a información política en los medios; entre la ola 1 y 2 , es impacto es de .11, entre la ola 2 y 3 , el impacto es de .17 y entre la ola 1 y 3 el impacto aumenta a .17.

Por lo tanto, el resultado es contrario a los estudios de Marcus, McKuen y Neumann (2011) sobre el papel de la ansiedad (como emoción negativa) y del sistema de "vigilancia", en la atención a noticias; y es más consistente con los resultados de 
Valentino et al (2011) sobre el papel movilizador de las emociones positivas, aunque también lo contradice parcialmente, en cuanto al papel movilizador del enojo. En el caso de la campaña presidencial de julio 2018, detectamos que, a más emociones positivas, mayor atención a las noticias.

Este resultado se matiza tomando en cuenta la cercanía partidista. En el caso de los panistas hay mayor impacto de la atención a las noticias sobre las emociones entre la ola 2 y la ola 3 (después de la campaña); el mismo efecto se observa entre los priistas entre la ola 1 y la ola 2. En otras palabras, se confirman los postulados de la teoría de la evaluación cognitiva para estos dos segmentos en estos momentos del levantamiento. Entre los morenistas también se detecta un cambio entre la ola 2 y la ola 3 (después de la campaña), cuando es mayor el impacto de la atención en la política en medios sobre las emociones: esto es, a mayor atención a noticias, mayores emociones positivas (pero matizando con que el índice de emociones está cargado hacía las emociones negativas). Mismo efecto de la atención a medios sobre las emociones entre la ola 2 (campaña) y 3 (resultados) se dio entre los cercanos a otros partidos. Pero no es el caso de los independientes: en este caso, hay un cambio en la última etapa de la campaña, cuando son las emociones las que impactan en la atención política a los medios. Esto es, la teoría de la inteligencia afectiva se aplica solo en el caso de los independientes, aunque matizando de acuerdo a la discusión de Ladd y Lentz (2008 y 2011), quienes trabajaron con el reverso de la ansiedad, el entusiasmo, y obtuvieron resultados parecidos al efecto movilizador de la ansiedad. En la interpretación de nuestros resultados tenemos que tomar en cuenta la ambivalencia de los mismos: si bien el índice de emociones utilizado tiene una evolución hacia las emociones positivas en las tres olas, la valencia positiva de las emociones en estas tres olas está por debajo de la media teórica, por lo tanto, cargadas hacia las emociones negativas. Nuevamente, nos remitimos a la observación sobre la dimensión contextual y coyuntural de las emociones, como lo encontraron en su estudio comparativo van Zomeren et al. (2018), lo que también nos permite usar varios lentes teóricos que se complementan entre sí.

Sería materia de otros análisis desglosar el papel de cada una de las emociones en la atención a los medios, así como en otros indicadores de participación política, tanto de bajo como de alto costo, incluyendo la intención de voto o preferencia por candidato. Por ahora, y junto con los autores revisados, queremos enfatizar el importante papel de las emociones en los estudios de actitudes, participación y comportamiento político, así como la complementariedad de las varias perspectivas teóricas sobre las emociones y la participación política. Más aun tomando en cuenta la valencia de las emociones en el contexto peculiar de las elecciones mexicanas de julio de 2018, donde las emociones sociales (como el enojo) se acumularon en el sexenio previo y tuvieron, sin duda, un papel importante en el desenlace de 1ero de julio, junto con las emociones positivas que se despertaron y se propagaron con la campaña electoral, como la esperanza, la alegría y el entusiasmo. 


\section{Referencias bibliográficas}

ABELSON, R. P., KINDER, D. R., PETERS, M. D. y FISKE, S. T. (1982). Affective and semantic components in political person perception. Journal of Personality and Social Psychology, 42 (4), pp. 619-630, doi:https://doi.org/10.1037/00223514.42.4.619

AGUILAR, R. (2013): ¿Emociones y Razón? El uso estratégico de las emociones en los anuncios de campaña presidencial de 2012. Política y gobierno, v. 20 (1), pp. 141-158.

ARFUCH, L. (2016). El "giro afectivo". Emociones, subjetividad y política". DeSignis: Publicación de la Federación Latinoamericana de Semiótica (FELS), (24), pp. 245-254.

ATHANASIOU, A., HANTZAROULA, P. y YANNAKOPOULOS, K. (2009): Towards a New Epistemology: The "Affective Turn". Historein, v. 8, DOI:http://dx.doi.org/10.12681/historein.33, pp. 5-16.

AUCEJO, B. (2018): El triunfo de AMLO en México, visto desde el dominio de las emociones. La Revista de ACOP, n. 0031, octubre, pp. 28-29.

BARBALET, J. (2002): Introduction: Why Emotions are Crucial, en Sociological Review, 50 (S2), pp. 1-9. DOI: 10.1111/j.1467-954X.2002.tb03588.x

(1998): Emotions, Social Theory and Social Action. A Macrosociological Approach. Cambridge, Cambridge University Press.

BRADER, T. (2005): Striking a Responsive Chord: How Political Ads Motivate and Persuade Voters by Appealing to Emotions. American Journal of Political Science, v. 49 (2), pp. 388-405.

(2006): Campaigning for Hearts and Minds: How Emotional Appeals in Political Ads Work, Chicago, Chicago University Press.

(2011): The Political Relevance of Emotions: "Reassesing" Revisited. Political Psychology, v. 32 (2), pp. 337-346, doi: 10.1111/j.1467-9221.2010.00803.x

CORDUNEANU, V.I. (2019): El papel de las emociones sociales y personales en la participación política. Revista Mexicana de Opinión Pública, año 14, n.26, pp. 7196.

GROENENDYK, E. (2011): Current Emotion Research in Political Science: How Emotions Help Democracy Overcome its Collective Action Problem, en Emotion Review, v. 3 (4), pp. 455-463, DOI: 10.1177/1754073911410746 
HOGGETT, P. y SIMPSON, S. (2012): Introduction, en HOGGETT, Paul y SIMPSON, Simon (ed.). Politics and Emotions. The affective turn in contemporary political studies. New York, Continuum.

JASPER, J.M. (2013): Las emociones y los movimientos sociales: veinte años de teoría e investigación, en Revista Latinoamericana de Estudios sobre Cuerpos, Emociones y Sociedad. Año 4 (10) pp. 48-68.

KENNY, D.A. y HARACKIEWICZ, J. M. (1979): Cross-lagged panel correlation: Practice and promise. Journal of Applied Psychology, v. 64(4), 372-379. doi: 10.1037/0021-9010.64.4.372

LADD, J.MD. y LENZ, G. S. (2008): Reassessing the Role of Anxiety in Vote Choice. Political Psychology, v. 29 (2), pp. 275-296.

(2011): Does Anxiety Improve Voter's Decision Making? Political Psychology, vol. 32 (2), pp. 347-361 doi: 10.1111/j.1467-9221.2010.00805.x.

LARA, A. y ENCISO, G. (2013): El Giro Afectivo. Athenea Digital, v. 13 (3), pp. 101-119.

LODGE, M. y TABER, C.S. (2005): The Automaticity of Affect for Political Leaders, Groups and Issues: An Experimental Test of the Hot Cognition Hypothesis. Political Psychology, v. 26 (3), 2005, pp. 455- 481.

LOPEZ-ESCOBAR, E., LLAMAS, J.P., MCCOMBS, M., y LENNON, F.R. (1998): Two level of agenda setting among advertising and news in the 1995 Spanish elections. Political Communication, 15(2), pp. 225-238. doi: 10.1080/10584609809342367

MARAÑON, F., MUÑIZ, C. y SALDIERNA, A.R. (2017) La persuasión política en campañas electorales: Cuasi-Experimento sobre el efecto del uso de Rutas Persuasivas de los Spots Políticos. Daena: International Journal of Good Conscience, v. 12 (2), pp. 148-158).

MARCUS, G.E. (1988). The Structure of Emotional Response: 1984 Presidential Candidates. American Political Science Review, v. 83 (3), pp. 737-761, DOI: $10.2307 / 1962488$. 250.

(2000): Emotions in Politics. Annual Review of Political Science, v. 3, pp. 221 
MARCUS, G.E., MACKUEN, M. y NEUMAN, W. R. (2011): Parsimony and Complexity: Developing and Testing Theories of Affective Intelligence. Political Psychology, v. 32 (2), pp. 323- 336. doi: 10.1111/j.1467-9221.2010.00806.x

MORRIS, J.P., SQUIRES, N.K., TABER, C.S. y LODGE, M. (2003): Activation of Political Attitudes: A Psychophysiological Examination of the Hot Cognition Hypothesis. Political Psychology, v. 24 (4), pp. 727-745.

REDLAWSK, D.P., TOLBERT, C.J. y FRANKO, W. (2010): Voters, Emotions and Race in 2008: Obama as the First Black President. Political Research Quarterly, v. 63 (4), pp. 875-889.

ROBERTS, M. y MCCOMBS, M. (1994): Agenda setting and political advertising: Origins of the news agenda. Political Communication, v. 11 (3), pp.249-262. doi: 0.1080/10584609.1994.9963030.

TABER, C. y LODGE, M. (2006): Motivated Skepticism in the Evaluation of Political Beliefs. American Journal of Political Science, v. 50 (3), pp. 755-769.

(2016): The Illusion of Choice in Democratic Politics: The Unconscious Impact of Motivated Political Reasoning. Advances in Political Psychology, v. 37, suppl. 1, 2016, pp. 61- 85, doi: 10.1111/pops.12321.

VALENTINO, N.A., BRADER, T., GROENENDYK, E.W., GREGOROWICZ, K. y HUTCHINGS, V.L. (2011): Election Night's Alright for Fighting: The Role of Emotions in Political Participation. The Journal of Politics, v. 73 (1), pp. 156-170. doi:10.1017/S0022381610000939.

VAN ZOMEREN, M., SAGUY, T., MAZZONI, D. y CICOGNANI, E. (2018): The curious, context-dependent case of anger: Explaining voting intention in three different national elections. Journal of Applied Social Psychology, n. 48, pp. 329338, DOI: 10.1111/jasp.12514.

WAHL-JORGENSEN, K. (2016): The Emotional Politics of the EU Referendum: Bregrexit and Beyond, en EU Referendum Analysis 2016: Media, Voters and the Campaign. Early Reflections from leading UK Academics, JACKSON, D., TORSEN, E. y Wring, D., (Eds), p. 116, Center for the Study of Journalism, Culture and Community, Bournemouth University, Center for Politics and Media Research (Bournemouth University), The Center for Research in Communication and Culture (Loughborough University), PSA The Media and Politics Group, Loughborough University, disponible en https://www.referendumanalysis.eu/ (consultado 20-122018).

WANG, C.H. (2013): Why Do People Vote? Rationality or Emotion. International Political Science Review, v. 34 (4), pp. 483-501 DOI: 10.1177/0192512113490365. 
WESTEN, D. (2007). The Political Brain: The Role of Emotion in Deciding the Fate of the Nation. Perseus Publishing. 